\title{
How does the Asian summer precipitation-ENSO relationship change over the past 544 years?
}

\author{
Hui Shi ${ }^{1} \cdot$ Bin Wang ${ }^{1,2}$
}

Received: 12 April 2018 / Accepted: 8 August 2018 / Published online: 23 August 2018

(c) The Author(s) 2018

\begin{abstract}
The secular change of the Asian monsoon (AM)-El Niño-Southern Oscillation (ENSO) relationship has been recognized as a specter for seasonal forecast. The causes of such changes have not been well understood. How the monsoon-ENSO relationship underwent secular changes beyond instrumental period has rarely been discussed. Here we explore the multidecadal to centennial changes of the AM-ENSO relationship with the recently compiled Reconstructed Asian summer Precipitation (RAP) dataset (1470-2013) and multiple ENSO proxy indices. During the past five centuries, two leading modes of interannual variability of RAP are found to be associated with the ENSO developing and decaying phases, respectively. The mechanisms behind the modern monsoon-ENSO relationship can reasonably well explain the past monsoon behavior. In response to a developing ENSO, precipitation anomalies from the Maritime Continent (MC) via India to northern China are in phase, and this "chain reaction" tends to be largely steady since around $1620 \mathrm{AD}$ when the Indian summer monsoon abruptly strengthened. Further, the strengthening of the link between developing-ENSO and Indian-northern China rainfall since 1620 AD concurred with a phase reversal of the Pacific Decadal Oscillation. During the decaying phase, however, the summer rainfall-ENSO relationship over the Yangtze River Valley-southern East China (YRV-SEC), the MC and central Asia, has gone through large multidecadal to centennial changes over the past five centuries. A remarkable reversal of sign in the AM-decaying ENSO relationship occurred roughly from 1740 to 1760 over the YRV-SEC and MC, which may be associated with the long-term strengthening of ENSO intensity. Future research should continue focusing on revealing the possible causes of the low-frequency changes in the monsoon-ENSO relationship using general circulation models and paleoclimate proxy reconstructions.
\end{abstract}

Keywords Reconstructed Asian summer precipitation · Asian monsoon-ENSO relationship · Niño reconstruction · Multidecadal to centennial change $\cdot$ Nonstationarity.

\section{Introduction}

The Asian monsoon (AM) system has been extensively studied owing to its great significance and dynamic complexity (Wang 2006). On the interannual timescale, the seasonal evolution of ENSO is a major pace-maker of the AM variability (e.g., Rasmusson and Carpenter 1983; Ropelewski and Halpert 1987; Webster and Yang 1992; Wang et al. 2003,

Bin Wang

wangbin@hawaii.edu

1 Department of Atmospheric Sciences, School of Ocean and Earth Science and Technology, University of Hawaii at Manoa, Honolulu, HI 96822, USA

2 Earth System Modeling Center, Nanjing University of Information Science and Technology, Nanjing, China
2015). During the El Niño developing phase, the Indian summer monsoon (ISM) tends to weaken (e.g., Walker and Bliss 1932; Shukla and Mooley 1987; Webster et al. 1998; Sikka 1980; Keshavamurty 1982; Mooley and Parthasarathy 1984) due to the suppressed convection over the Maritime Continent (MC) caused by the eastward shift of the Walker circulation (e.g., Palmer et al. 1992; Lau and Nath 2000); meanwhile the northern East Asian summer monsoon (EASM) also tends to weaken in phase with the ISM (e.g., Yatagai and Yasunari 1995; Kripalani and Kulkarni 2001; Enomoto et al. 2003). During the decaying phase of an El Niño event, the subtropical EASM and the Meiyu/Baiu frontal rainfall tend to enhance (e.g., Fu and Teng 1988; Huang and Wu 1989; Zhang et al. 1996; Lau and Sheu 1988; Chang et al. 2001) through the variation of the western North Pacific (WNP) subtropical high and its interaction 
with underlying Indo-Pacific warm pool (Wang et al. 2000, 2013). For a more detailed review of the East Asian monsoon, readers are referred to Wang and $\mathrm{Li}$ (2004). If one does not distinguish between the developing and decaying phase of El Niño (La Niña), the simultaneous correlation between summer rainfall in East Asia and the SST anomalies in the eastern equatorial Pacific would not be significant during instrumental period (Chen et al. 1992).

In a longer time frame, historical megadroughts and monsoon failures in Asia are found associated with strong El Niño events (Cook et al. 2010; Feng et al. 2013). The footprint of ENSO is also found embedded in drought reconstructions over Asia ( $\mathrm{Li}$ et al. 2014) and warm season precipitation reconstructions over China for the past 500 years (Shi et al. 2017). These studies indicate that ENSO played an important role in the past AM variability. However, the ENSO phase-dependent features of the Asian precipitation anomalies have not been fully addressed with proxy data. Although one of these studies (Li et al. 2014) distinguishes between the monsoon responses to ENSO developing and decaying phases, the results are limited to South Asia and MC sectors. No evident signal is found in the EASM, likely due to the limitation of the Monsoon Asia Drought Atlas (MADA, e.g., Yang et al. 2013, 2014) used in the study.

The AM-ENSO relationships are tantalizing due to the effects of local air-sea interaction, land surface anomalies, as well as impacts of one monsoon subsystem on another. For example, the atmosphere-ocean interaction generates the Indian Ocean Dipole (IOD) mode, which affects the ISM variability (Saji et al. 1999; Webster et al. 1999; Li et al. 2003; Wang et al. 2003; Ashok et al. 2004, 2001). The local cloud-radiation-SST feedback over the northern Indian Ocean also affects the ISM and tends to offset the ENSO impacts (Lau and Nath 2000). The Himalayan/Eurasian snow cover has been identified as an important remote forcing of the AM besides the ENSO (e.g., Blanford 1884; Hahn and Shukla 1976; Barnett et al. 1989; Yang 1996). Within the AM system, the anomalous ISM convection also impacts the northern EASM variability (Wu and Wang 2002). Whether these impacts on the past AM-ENSO relationships have been recorded with paleoclimate proxies is unknown.

What's more complicated is that the AM-ENSO relationship is nonstationary. Since the late 1970s, the ISM-ENSO relationship has been observed to have weakened or broken down (e.g., Kumar et al. 1999), accompanied by a reversed relationship between the northern EASM and ENSO during the decaying El Niño phrases around the same time (Wu and Wang 2002). On the other hand, Wang et al. (2008) showed that the relationships between ENSO and the western North Pacific, East Asian, and Indonesian monsoons have all become enhanced during ENSO's developing, mature, and decaying phases. Thus, the overall coupling between the Asian-Australian monsoon system and ENSO has been strengthened.

The non-stationarity of the Indian monsoon-ENSO relationship has been recognized as a specter for seasonal forecast (Webster et al. 1998). The recent weakening of the ISMENSO relationship has been associated to various factors such as anthropogenic warming (e.g., Kumar et al. 1999; Ashrit et al. 2001), interdecadal variations (e.g., Chang et al. 2001; Feba et al. 2018; Krishnamurthy and Krishnamurthy 2014; Wang et al. 2008) and random weakening due to interference by other interannual phenomenon (e.g., Ashok et al. 2001; Ashok and Saji 2007). The answer is not yet clear. A potential better understanding of the cause(s) could be obtained with long records that cover more cycles of such interdecadal changes under different mean climate. However, how the monsoon-ENSO relationship underwent secular changes on the interdecadal-centennial timescale beyond instrumental period has rarely been discussed.

This study aims to use a new 544-year Reconstructed Asian summer Precipitation (RAP) dataset to investigate how the AM responds to ENSO evolution. One question we are trying to address is to what degree the proposed mechanisms for the current AM-ENSO relationship remain applicable to the past AM-ENSO relationship. We also attempt to detect how the AM-ENSO relationship has changed over the past five centuries and explore what caused these changes. Section 2 introduces the RAP dataset, and describes the observational data and other proxy records used, as well as methodology. Section 3 discusses the long-term leading modes of the AM interannual variability and their dynamical ties with ENSO phases. Section 4 presents the secular changes of the AM-ENSO relationship in the past 544 years, followed by discussion (Sect. 5) and conclusions (Sect. 6).

\section{Data and methods}

The RAP dataset is a gridded 544-year (from AD 1470 to 2013) summer precipitation reconstruction generated by merging two complementary proxies including 453 tree ring width chronologies and 71 historical documentary records over the Asian land region $\left(8.75^{\circ} \mathrm{S}-55.25^{\circ} \mathrm{N}\right.$, $61.25^{\circ} \mathrm{E}-143.25^{\circ} \mathrm{E}$ ) (Shi et al. 2018). The RAP dataset shows significantly improved data quality compared with single-type proxy reconstructions, and skillful reconstruction is found over East and North China, northern India and Pakistan, the Indochina Peninsula, mid-latitude Asia, the MC, and southern Japan. The RAP dataset has also been proved to well capture the large-scale year-to-year rainfall variability over monsoon Asia, arid central Asia, and entire Asia during the twentieth century. Specifically, the RAP captures the abrupt strengthening of ISM in the 1600s recorded by other proxies (Anderson et al. 2002; 
Sinha et al. 2011); to a larger extent, it shows relatively weak ISM during the Little Ice Age (fifteenth to nineteenth centuries, Bradley and Jonest 1993) in comparison with that during the industrial period as shown from other studies (Sinha et al. 2007; Tejavath et al. 2017).

To examine the long-term leading interannual variability modes of the Asian summer precipitation, we first applied detrend and an 8-year high-pass filter to the data. The rotated empirical orthogonal function (REOF) analysis is used because it tends to yield more regionally confined patterns and is thus more appropriate for the purpose of studying the regional monsoon-ENSO relationships. A correlation-based K-mean cluster analysis (Seber 1984; Spath 1985) was also conducted to illustrate the regionality of the RAP. Global sea surface temperature (SST) from the Hadley Center Sea Ice and Sea Surface Temperature dataset (HadISST, Rayner 2003) within a period from 1870 to 2013 was used to examine the dynamic origins of the leading principal components (PCs).

To extend the monsoon-ENSO relationship back to the pre-instrumental period, we utilized ten conventional reconstructions of boreal winter ENSO indices for the past millennium, among which seven indices are developed from one or multiple types of proxies (e.g., tree rings, coral, ice core, and sediment) with global coverage (Stahle et al. 1998; Mann et al. 2000; McGregor et al. 2010; Wilson et al. 2010; Li et al. 2011, 2013; EmileGeay et al. 2013) and three are derived solely from the tree rings in southwest North America (D'Arrigo et al. 2005; Cook et al. 2008; Braganza et al. 2009).

To evaluate the quality of the reconstructed Niño indices, the observed Niño 3.4 index from the HadISST1 dataset (Rayner 2003), and the Global Precipitation Climatology Centre (GPCC) monthly precipitation dataset from 1901 to present (Schneider et al. 2015) were used. Pattern correlation coefficients (PCCs) and normalized root mean square errors (NRMSEs) between the observed and reconstructed rainfall-ENSO relationship were calculated so as to determine the "best estimates" of the past ENSO variability.

Selected Niño proxies were used to further demonstrate the long-term AM-ENSO relationship. Each AM subsystem was represented by an area-weighted averaging index over the corresponding region. Rolling correlations with 11- and 51-year windows between monsoon and Niño indices were examined and discussed both individually and collaboratively.

\section{Long-term leading modes of the interannual variability of the RAP (1470-2013)}

\subsection{Rotated EOF modes}

The Asian summer monsoon rainfall variability has been studied primarily on regional scales, such as in India, East Asia, the WNP and the MC (e.g., Kumar et al. 1999; Ding and Chan 2005; Wang et al. 2000; Chang 2004). Lau and $\mathrm{Wu}$ (2001) studied the rainfall-SST co-variability for a short period of 1979-1998 using singular value decomposition (SVD) analysis of the Asian summer monsoon rainfall and global SST anomaly (SSTA). They found that the first mode is a biennial mode and the second one is associated with La Niña development. Using REOF analysis, here we adopt long records to identify the major modes of Asian precipitation variability.

The first REOF mode displays coherent changes over India and the Yellow River Basin (Fig. 1a). It explains $12.2 \%$ of the total variance. Such a coherence of Indian and northern China variability has been observed with instrumental data (e.g., Yatagai and Yasunari 1995; Kripalani and Kulkarni 2001; Wu and Wang 2002) and speleothem records for past millennia on the annual, decadal (Berkelhammer et al. 2010) and longer timescales (Kathayat et al. 2016). It should also be noted that the Indonesian precipitation is in phase with Indian and northern China precipitation anomalies, which is a typical pattern during the El Niño/La Niña developing stage. The second REOF mode has a strong loading over the Yangtze River Valley (YRV) where the major subtropical frontal zone is located, while the loadings of the opposite sign are over northwest India and Pakistan, and northeast Asia (Fig. 1b). It explains $11.0 \%$ of the total variance.

The two leading REOF modes are in a general agreement with the results of the cluster analysis (Fig. 1c). Cluster 1 in the blue color corresponds to the large loading areas in the first REOF mode, including north Asia, India, and the Yellow River Basin in northeastern China. Cluster 2 in red corresponds to the large loading areas of the second REOF mode, including western China, southern East China, and southern Japan. We define the area-weighted averages of precipitation anomalies in the blue and red regions as Cluster Index 1 (CI1) and Cluster Index 2 (CI2), respectively. CI1 and CI2 are significantly correlated with REOF1 and REOF2, respectively. The corresponding correlation coefficient is $r=0.76(p<0.01)$ and $r=0.82$ $(\mathrm{p}<0.01)$, respectively (Fig. 1d, e). 

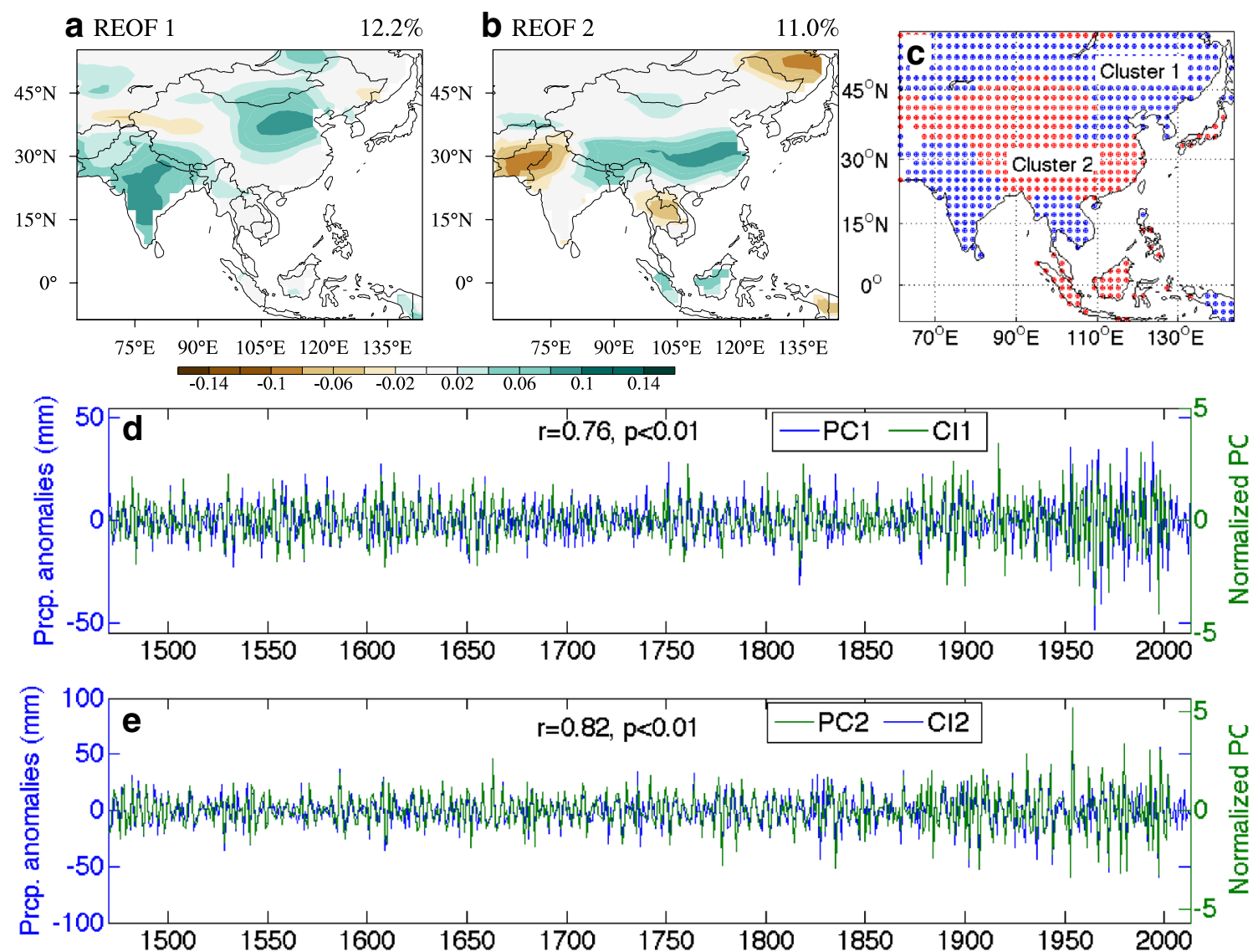

Fig. 1 The spatial patterns of the first two leading interannual REOFs (a, b) and the two clusters (c), as well as their corresponding temporal coefficients PC1/CI1 (d) and PC2/CI2 (e) derived from the RAP for the period from 1470 to 2013

\subsection{Origin of the two leading modes}

The linkages of the PCs with global SSTs are examined to understand their origins. The data covers the period of 1870-2013 when global SSTs are available. As shown in Fig. 2, the increased precipitation shown in REOF1 corresponds to a developing La Niña in the Pacific (Fig. 2a-e). Significant negative SST anomalies first appear over the cold tongue region in the preceding spring (March-April-May, Fig. 2b). The negative SSTs become stronger during summer (Fig. 2c) and maintain through the following fall (Fig. 2d) and winter (Fig. 2e). The results indicate that the increased rainfall over northern Asia, India, and the Yellow River Basin in northern China is associated with the development and maintenance of a La Niña-like condition. The power spectrum of PC1 has a pronounced 5-year peak that passes the $95 \%$ significance level, indicating its association with the low-frequency component of ENSO (Fig. 3a), which is reflected by the relatively slow development of La Niña (Fig. 2a-e).

The SST anomalies associated with PC2 suggest that REOF2 may be more closely associated with the El Niño decaying phase or a transition from warm to cold ocean conditions (Fig. 2f-j). An El Niño condition exists in the preceding winter (Fig. 2f). The anomalous warming disappears during the spring (Fig. 2g) and a La Niña-like SST pattern starts to develop from the summer to the following winter (Fig. $2 \mathrm{~h}-\mathrm{j}$ ), suggesting a rapid transition from warm to cold ocean conditions, which is a feature of quasi-biennial fluctuation. Spectral analysis confirms that strongest significant peaks of the PC2 range from 2.2 to 2.8 years (Fig. 3b), thus reflecting its association with the biennial component of ENSO (Fig. 2f-j).

The two major modes of variability identified here are consistent with the results of the EOF analysis of the Asian monsoon rainfall during the recent period of 1979-2010 made by Wang et al. (2015), who identified four major modes of variability. The first mode is an El Niño-La Niña developing mode, and the second one is an ENSO decaying mode, which is an Indo-western Pacific monsoonocean coupled mode. The agreement in the resultant two leading modes between our REOF and cluster analyses of the RAP and the EOF analysis of Wang et al. (2015) lends confidence for the RAP analysis and suggests that the two 


\section{PC1}
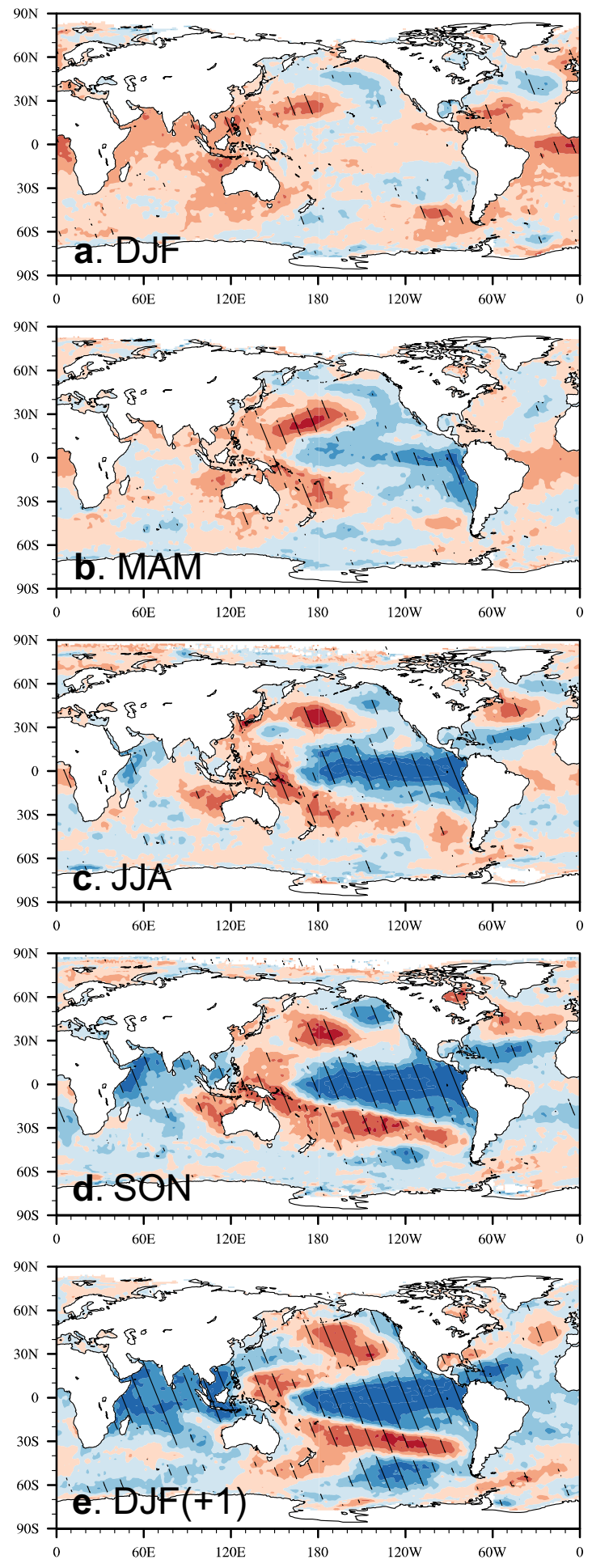

PC2
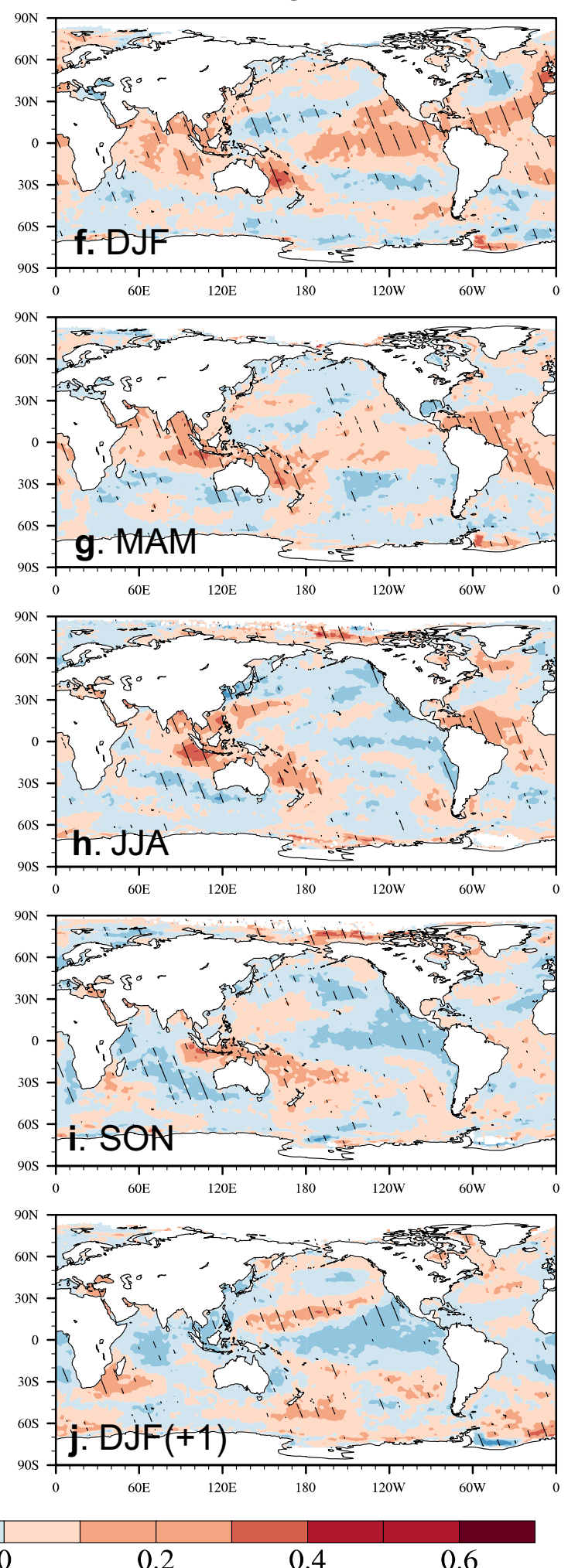

Fig. 2 Spatial patterns of correlations with global SSTs for PC1 (a-e) and PC2 (f-j) from 1870 to 2013. Hatched areas are significant correlations at the $90 \%$ level and higher (2-tailed) 
Fig. 3 Power spectra for PCs derived by using forward fast Fourier transformation, with $10 \%$ of the data tapered, and the modified Daniell window with a span of 4. Blue lines are the Markov Red Noise spectra. Red and orange dash lines indicate upper (lower) confidence bounds at 95 and $90 \%$ significance levels, respectively

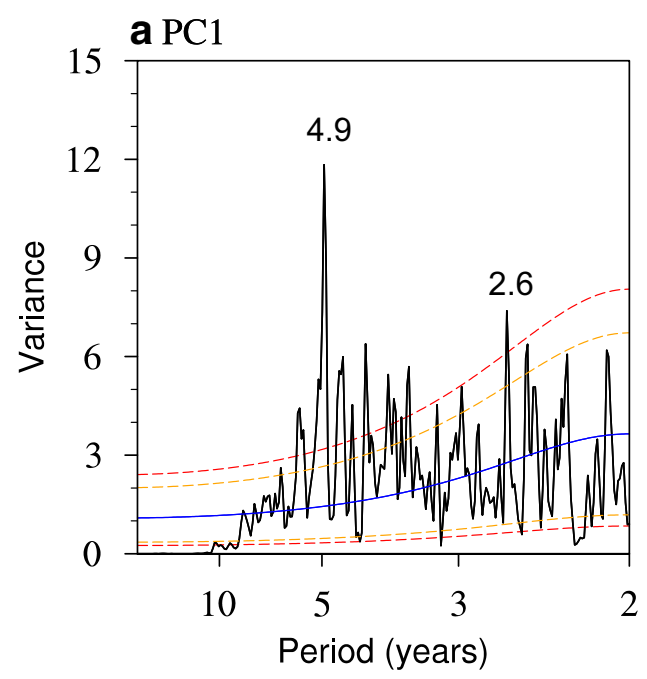

Table 1 Correlation coefficients between REOF PC1 (PC2) and Niño 0 (1) indices for the period of 1870 to 2010

\begin{tabular}{llll}
\hline & & REOF PC1 & PC2 \\
\hline Instrumental & Rayner et al. (2003) & $-0.42(\mathrm{p}<0.01)$ & 0.13 \\
Global proxy & Emile-Geay et al. (2013 & $-0.32(\mathrm{p}<0.01)$ & 0.07 \\
& Li et al. (2013) & $-0.38(\mathrm{p}<0.01)$ & 0.08 \\
& Braganza et al. (2009) & -0.09 & 0.02 \\
& Wilson et al. (2010) & $-0.32(\mathrm{p}<0.01)$ & 0.09 \\
& McGregor et al. (2010) & $-0.26(\mathrm{p}<0.01)$ & 0.10 \\
& Mann et al. (2000) & $-0.26(\mathrm{p}<0.01)$ & 0.09 \\
& Stahle et al. (1998) & $-0.27(\mathrm{p}<0.01)$ & 0.08 \\
& Li et al. (2011) & $-0.19(\mathrm{p}<0.05)$ & 0.14 \\
& Cook et al. (2008) & $-0.30(\mathrm{p}<0.01)$ & 0.12 \\
& D'Arrigo et al. (2005) & $-0.31(\mathrm{p}<0.01)$ & 0.09 \\
\hline
\end{tabular}

Numbers in italics indicate insignificant correlations. 0 and 1 denote ENSO develop and decay cases, respectively

leading modes are robust in both recent decades and the last 544 years. The order of the leading modes differs from those of Lau and $\mathrm{Wu}$ (2001), suggesting the increased importance of the slow (about 5 years) ENSO developing mode over a longer time period.

\subsection{Relationship between the leading patterns and Niño indices during 1870-2010}

Before study of the ENSO relationship with the leading modes derived from the RAP for the entire 544-year period, we first assess their relations during the instrumental period from 1870 to 2010 when the Niño proxies are more reliable.

Table 1 shows that correlations between $\mathrm{PC} 1$ and Niño (0) are relatively high and largely significant at the $1 \%$ confidence level, whereas correlations between PC2 and Niño (1) are insignificant. Here 0 denotes the ENSO developing year and 1 denotes the ENSO decaying year with respect to JJA rainfall, since ENSO tends to peak toward the end of the calendar year (0). The above result indicates that the relationship between the developing ENSO and summer (JJA) precipitation over the MC, India and northern China (REOF1) is robust. However, during the decaying phase of ENSO, the summer precipitation over the YRV (REOF2) is more variable and overall insignificant in response to the eastern Pacific SST anomalies.

The two types (global proxy- and North America (NA) tree ring-based) of indices show largely equal strength in their relations with the RAP, except that Braganza et al. (2009) and Li et al. (2011) show lower correlations (Table 1). Previous studies have shown a significant relationship between the tree ring width chronologies in NA and in Asia on the interdecadal and longer timescales (Fang et al. 2015; Li et al. 2013). One concern is that the correlations here between the RAP and the NA tree ringbased Niño indices could be largely due to the trees. We cannot completely rule out this possibility since the RAP is partially derived from the tree ring width chronologies in Asia, but the fact that the global proxy-based indices show similar correlations indicates that such relation is likely a true signal between precipitation and ENSO reflected by indices from various proxy types. Among the global-proxy based reconstructions, Li et al. (2013) uses the first two PCs from the MADA (Cook et al. 2010), which share some tree ring chronologies with the RAP over central Asia and the MC ( $\mathrm{Li}$ et al. 2014). We decided to retain $\mathrm{Li}$ et al. (2013) reconstruction, however, because (1) it shows good quality compared with observed DJF Niño index $(r=0.75$, $\mathrm{p}<0.01$ ); and (2) it is largely independent with the RAP in regions other than central Asia and the MC. Besides, sensitivity testing shows that excluding Li et al. (2013) Niño index would not change the conclusions. 
Figures 4 and 5 show the spatial patterns of correlations between Niño indices and rainfall during the ENSO developing and decaying phases, respectively. During the ENSO developing phase (Fig. 4), the observed Niño-monsoon (May-Oct.) relationship largely resembles the pattern of RAP REOF1. Niño index reconstructed by Li et al. (2013) shows the highest PCC and lowest normalized RMSE, followed by that of Cook et al. (2008) and Emile-Geay et al. (2013). During the decaying phase (Fig. 5), the PCCs are significantly lower. Niño index reconstructed by Cook et al. (2008) yields the best performance, followed by that of $\mathrm{Li}$ et al. (2013). Based on the above evaluations, we selected the top four, which are Niño reconstructions by Li et al. (2013), Emile-Geay et al. (2013), Cook et al. (2008) and D'Arrigo et al. (2005) to further analyze the long-term variability of the AM-ENSO relationship.

\section{Secular changes of the AM-ENSO relationship in the past 544 years}

In order to investigate the long-term relationship between the RAP and ENSO, we use the four proxy ENSO indices described in Sect. 2 and 3.

\subsection{ENSO developing phase}

Figure 6 shows the RAP response to developing El Niño events for the present (1901-2010, Fig. 6b) and the past (1470-1900, Fig. 6a). The pattern for the pre-1900 period largely resembles the one after 1900 , especially for the key monsoon subsystems. Reduced rainfall is found over India, northern China and the MC, whereas enhanced rainfall occurs over central Asia. Differences also exist. For example, the positive correlations over the western China $\left(35-45^{\circ} \mathrm{E}, 85-100^{\circ} \mathrm{E}\right)$ were negative before 1900 ; the negative correlations over southern China and along the Yangtze River after 1900 were nearly normal before 1900 .

Four regions of significant correlations are identified, including the $\mathrm{MC}\left(9^{\circ} \mathrm{S}-15^{\circ} \mathrm{N} ; 100-143^{\circ} \mathrm{E}\right)$, India $\left(11-30^{\circ} \mathrm{N}\right.$, $\left.61-87^{\circ} \mathrm{E}\right)$, northern China $\left(35-55^{\circ} \mathrm{N}, 103-120^{\circ} \mathrm{E}\right)$, and northwestern China-central Asia $\left(37-44^{\circ} \mathrm{N}, 65-85^{\circ} \mathrm{E}\right)$. Time evolutions of the summer precipitation-ENSO relationship over the four regions are shown in Fig. 7. The summer precipitation over the $\mathrm{MC}$ is significantly negatively correlated with the Niño indices except during the first half of the nineteenth century (Fig. 7a), and the average of the 51-year rolling correlation for all four indices is -0.31 . It's also noteworthy that the relationship is largely stable over time on multidecadal to centennial timescales (lines in Fig. 7a).

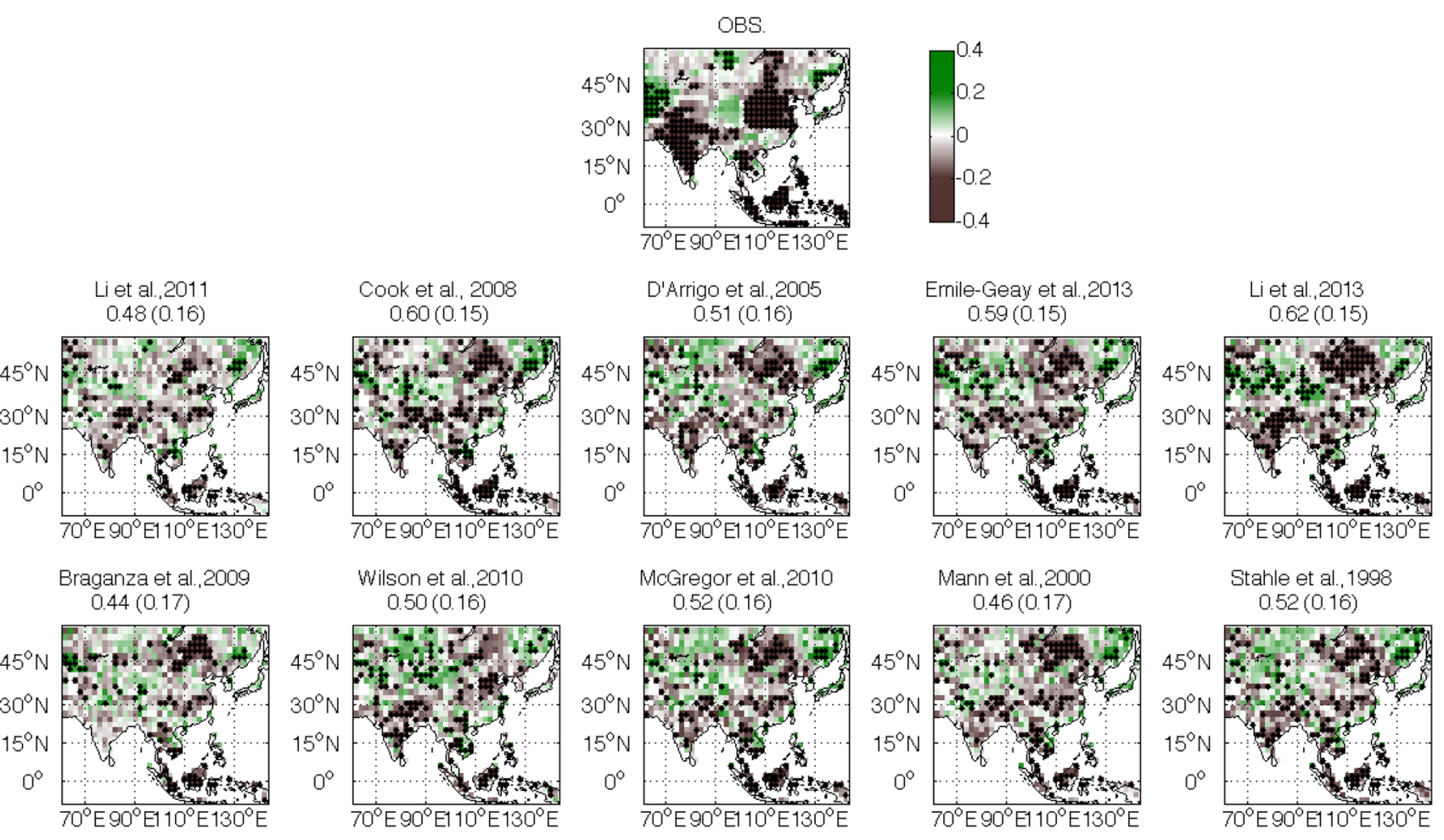

Fig. 4 Spatial patterns of correlations between Niño indices and the RAP during ENSO developing years from 1901 to 2010 in comparison with observed correlation map. Dotted areas are significant corre- lations at the $90 \%$ level and higher (2-tailed). Numbers are PCCs and numbers in prentices are normalized RMSEs 


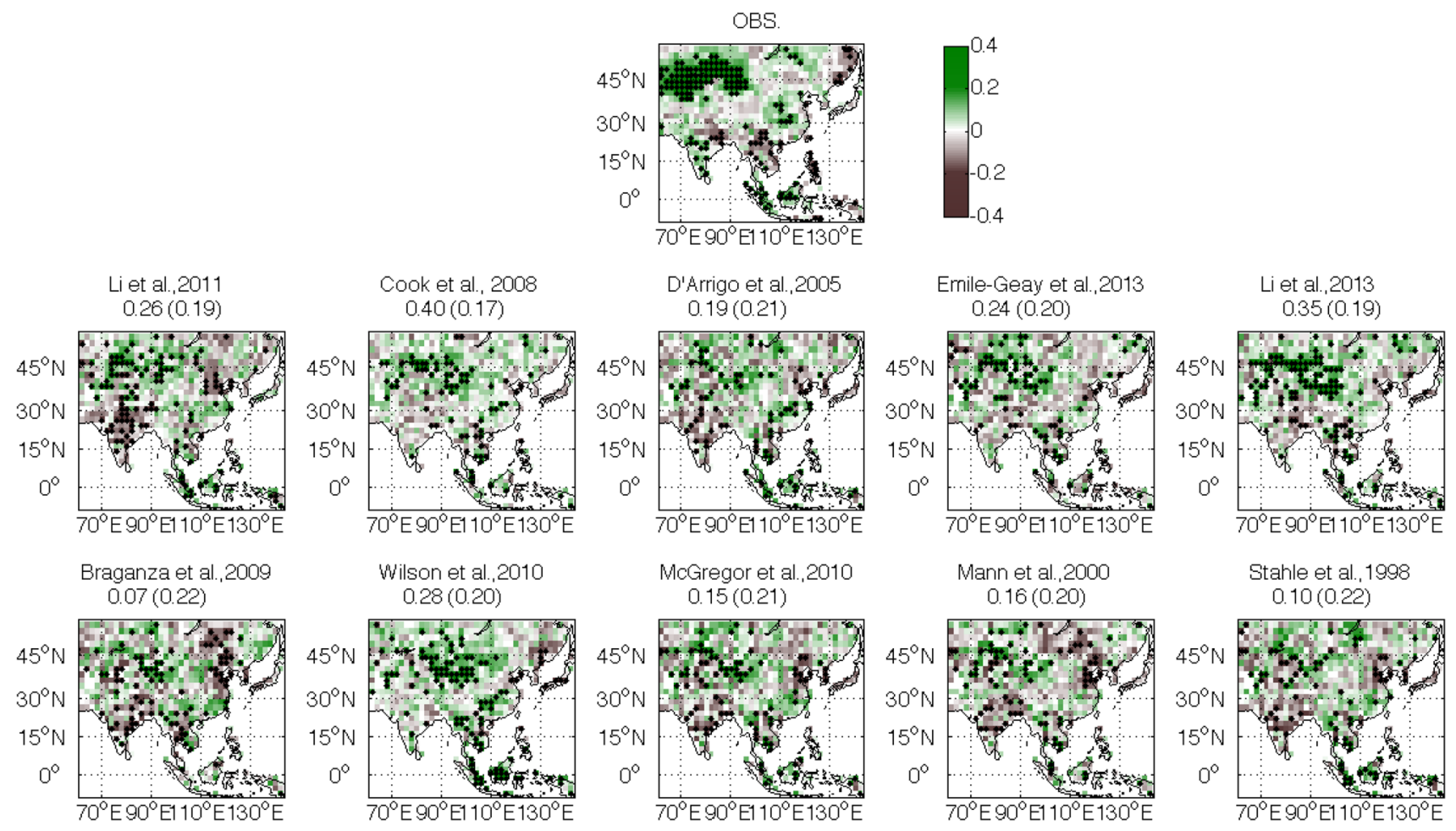

Fig. 5 Same as Fig. 4, except for the relationship between Niño indices and the RAP during the ENSO decaying years

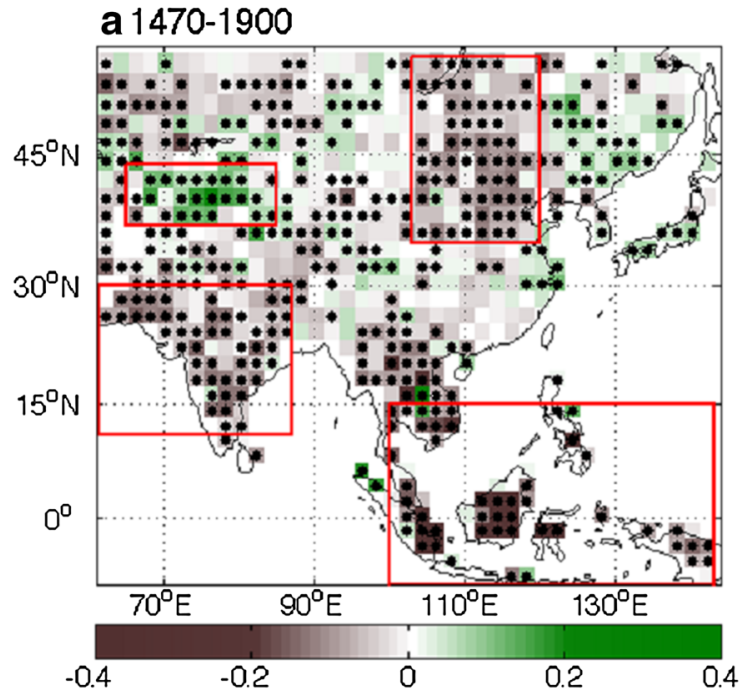

Fig. 6 Relationship between Asian summer precipitation and developing ENSO events. Spatial patterns of correlations between Niño index and the RAP in ENSO developing years for the periods of a

Slightly weakened correlations appear between 1740 and 1840. The relationship becomes strong after around 1860 to the end of the twentieth century. On the interdecadal timescale (shading in Fig. 7a), very few breaks of positive correlation occur around 1800 , but they are not significant (Fig. 7a). Meanwhile negative correlations dominate (overall

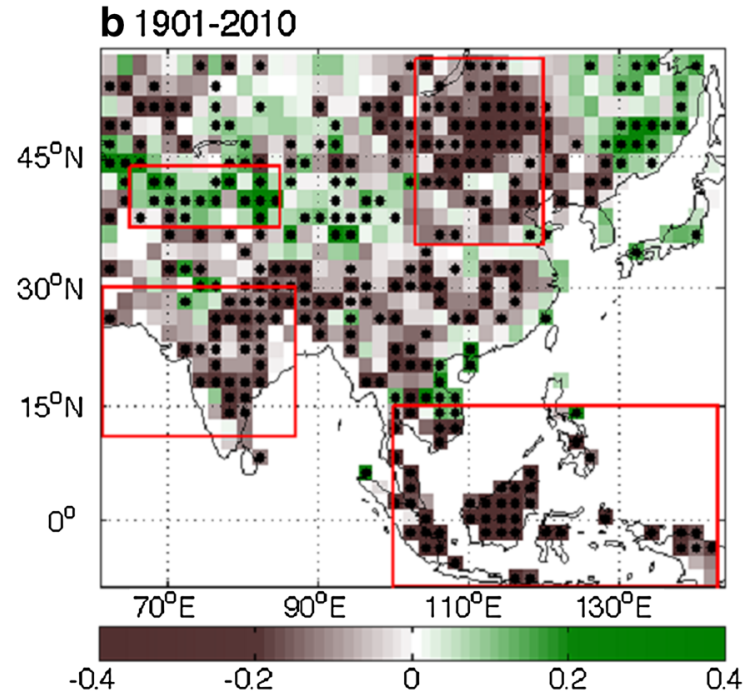

1470-1900 and b 1901-2010. Maps are averaged from four Niño reconstructions. Dotted areas are significant correlations at the $90 \%$ level and higher (2-tailed)

$r=-0.33)$, and significant negative correlations are more frequent.

The Indian rainfall-ENSO relationship (Fig. 7b) is overall negative $(r=-0.16)$. However, large fluctuations appear with periods of insignificant correlations and zero or slightly positive correlations on multidecadal to centennial 
Fig. 7 11-year (shadings) and 51-year (lines) rolling correlations between Niño indices and the rainfall indices in ENSO developing years. Shadings are averages of four Niño reconstructions. Gray Lines are individual Niño indices and black line is the average of them. Dotted lines are cutoff correlations at the $90 \%$ significance level with $n-2$ degree of freedom (orange lines: $\mathrm{DOF}=9$, gray lines: $\mathrm{DOF}=49$ )
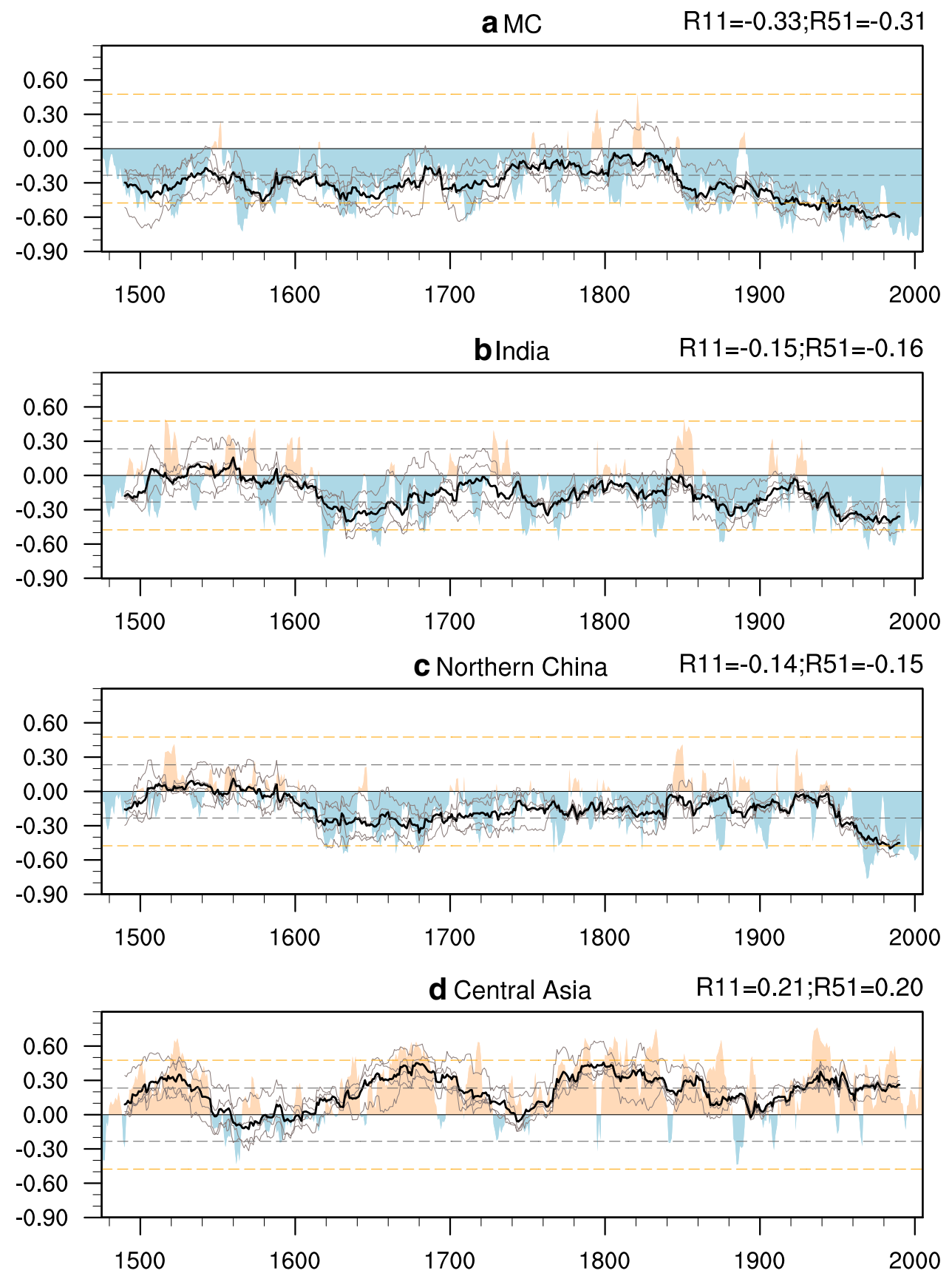

timescales (lines in Fig. 7b). On the interdecadal timescale (shading in Fig. 7b), decades of positive correlations are found around 1520, 1570, 1730, and 1850, albeit insignificant. A similar case is found with respect to the northern China rainfall-ENSO relationship (Fig. 7c). In fact, the correlations between the Indian rainfall-ENSO and northern China rainfall-ENSO relationships are as high as 0.72 on the interdecadal timescale, and 0.79 on multidecadal to centennial timescales, indicating coherent low-frequency changes over the two regions for the past 500 years. Periods with a strong ENSO tie are seen from around 1620 to 1700 , and from around 1950 to 1990 for both India and northern China
(Fig. 7b, c), which coincide with the periods of strengthened MC rainfall-ENSO correlations (Fig. 7a). It is noteworthy that the ENSO tie with the Indian and northern China rainfall seems to be strengthened since 1620, which nearly concurs with a well-documented abrupt strengthening of the Indian summer monsoon during the 1600s, as shown in upwelling proxy (Anderson et al. 2002), speleothem records (Sinha et al. 2011) and the RAP (Shi et al. 2018). For the period of 1620-2010, the correlation coefficient between Indian monsoon rainfall and ENSO is $-0.23(\mathrm{p}<0.01)$ and that between the northern China rainfall and ENSO is -0.19 $(\mathrm{p}<0.01)$. 
The central Asia rainfall-ENSO relationship is largely positive on both interdecadal $(\mathrm{r}=0.21)$ and longer timescales $(r=0.20)$ (Fig. 7d). After 1620 AD, significant positive correlations often occur during the periods of strong negative AM-ENSO correlations (Fig. 7a-c), suggesting likely opposite phases between the AM-ENSO relationship and the arid central Asia-ENSO relationship.

\subsection{ENSO decaying phase}

For the ENSO decaying phase, in a similar fashion, we show the rainfall-ENSO relationship before (Fig. 8a) and after 1900 (Fig. 8b). Apparent differences are found between the two. First, positive correlations are found over a large area of central Asia-northwestern China after 1900, but the relationship is more inhomogeneous before 1900. Second, significant negative correlations are found over India and northern China before 1900, but very few significant correlations exist after 1900. Third, positive correlations are located over the southeastern China before 1900, while after 1900 they are located over the YRV. Fourth, over the MC, the correlations are largely negative before 1900 , while positive correlations prevail after 1900 . These remarkable differences suggest that during ENSO decaying phases the Asian rainfall-ENSO relationship might be very variable over the past five centuries and what is seen today is not a robust long-term signal.

To find out the changing points of decaying ENSOAM rainfall relationship over the past 544 years, we take three regions of interest to examine the time evolution of the precipitation-ENSO relationship during the decaying phase of ENSO, which are the Yangtze River Valleysoutheastern China (YRV-SEC, $23-33^{\circ} \mathrm{N} ; 105-125^{\circ} \mathrm{E}$ ), the $\mathrm{MC}\left(9^{\circ} \mathrm{S}-9^{\circ} \mathrm{N} ; 95-143^{\circ} \mathrm{E}\right)$, and central Asia $\left(35-50^{\circ} \mathrm{N}\right.$, $\left.65-100^{\circ} \mathrm{E}\right)$.

As shown in Fig. 9, the relationship is nonstationary for all three regions indicated by the three indices on both interdecadal timescale (shading) and multidecadal to centennial (lines) timescales. The YRV-SEC rainfallENSO and MC rainfall-ENSO relationships seem to undergo similar low-frequency changes throughout the past 500 years (Fig. 9a, b). The correlation between the two rainfall-ENSO relationships is $0.51(0.39)$ on the centennial (interdecadal) timescale. A noticeable centennial shift from negative to positive relationship is found during 1740 to 1760 (lines in Fig. 9a, b). After 1760, the YRV-SEC-ENSO relation is overall positive $(r=0.15$, $\mathrm{p}<0.05$ ). Another centennial shift is found in the middlelate sixteenth century but less evident. These results suggest that during the ENSO decaying phase the relationship between ENSO and Asian summer monsoon rainfall over the YRV-SEC and MC is highly variable on the centennial time scale. The Central Asia rainfall-ENSO relationship (Fig. 9c) is less coherent with those between ENSO and YRV-SEC and MC rainfall. After 1700, the correlation is largely positive $(r=0.20, p<0.01)$; before 1700 , the relation is more variable $(\mathrm{r}=-0.02$, insignificant). The mid-eighteenth century change in the YRV-SEC (MC) rainfall-ENSO relationship is evident. The cause of such a sudden change deserves further investigation, probably through numerical experiments.
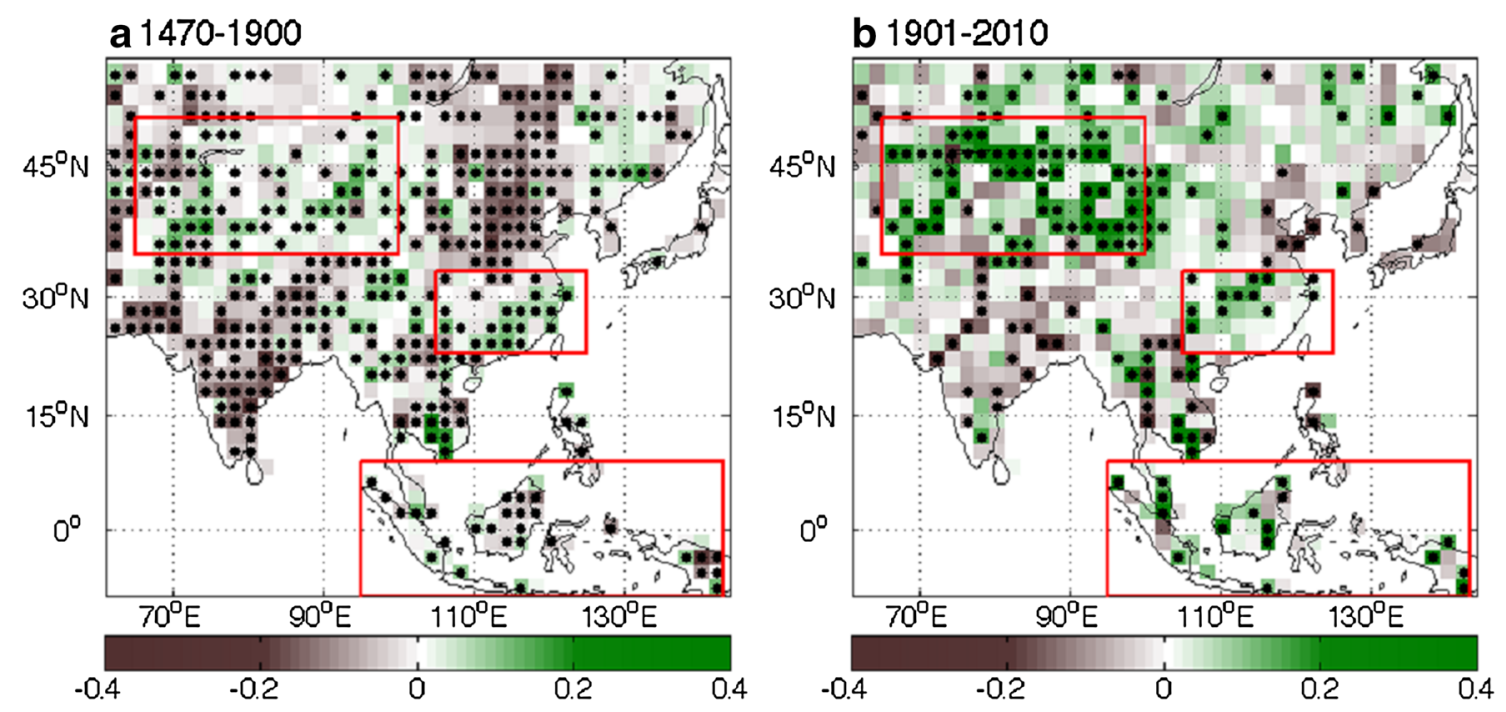

Fig. 8 Relationship between Asian summer precipitation and decaying ENSO events. Same as Fig. 6, except for the summer precipitation in ENSO developing years 
Fig. 9 Same as Fig. 7 except for the correlations between Niño indices and the rainfall indices in ENSO decaying years
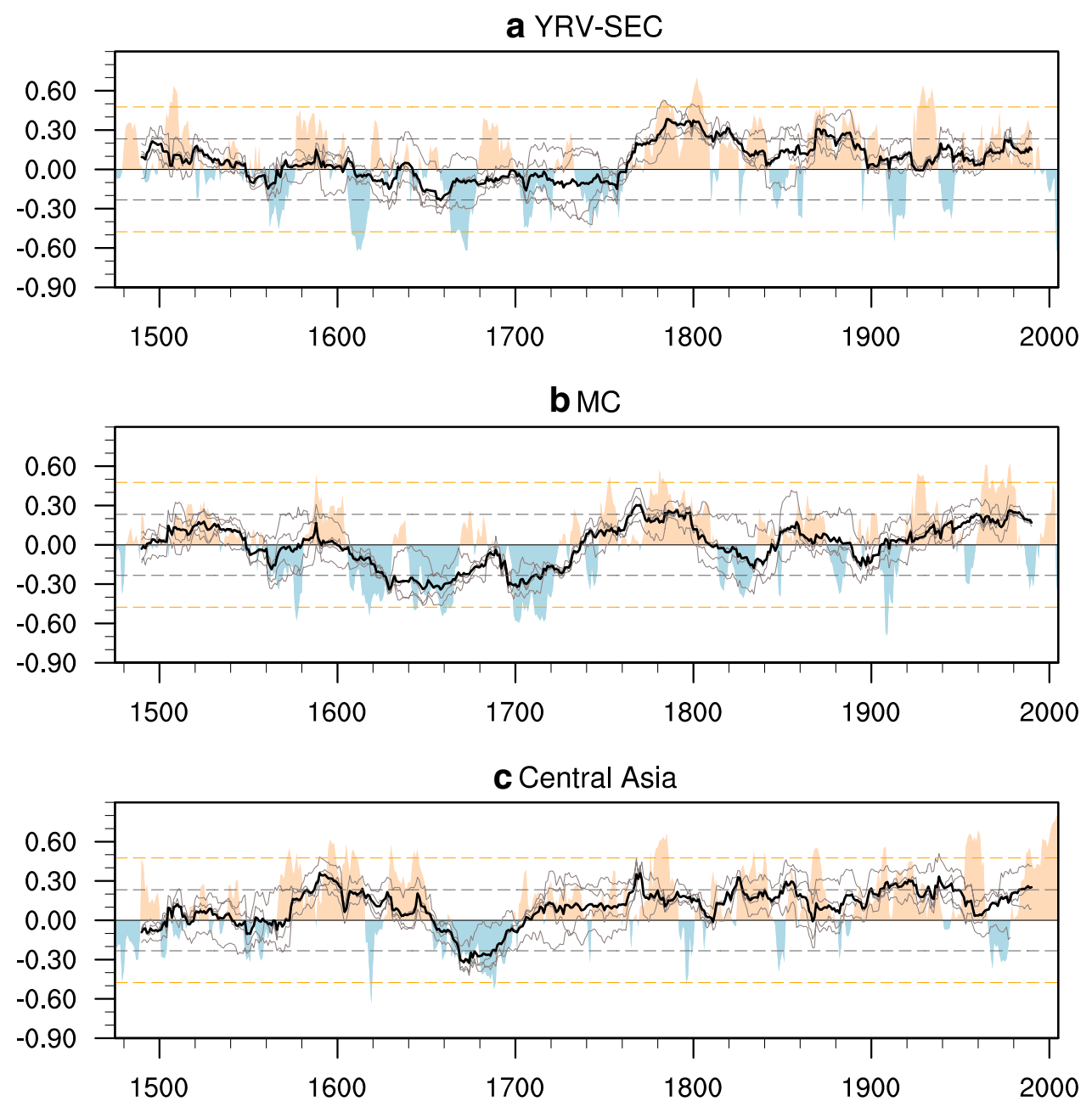

\section{Discussion}

\subsection{Mechanisms of the monsoon-ENSO relationship: present and the past}

Wang and Fan (1999) identified two major convective heat sources that drive the Asian summer monsoon system, thus distinguishing the ISM variability with the WNP-EASM variability. The former is impacted by the heat source centered in the Bay of Bengal-India-Arabian Sea region, and the latter is controlled by the convection center anchored in the South China Sea and the Philippine Sea. ENSO affects Asian summer monsoon through changing the two convective heat sources directly and indirectly (Wang et al. 2001).

During a La Niña developing stage, convection over the $\mathrm{MC}$ is enhanced under the direct response to the enhanced Walker circulation due to atmospheric equatorial wave adjustment. The enhanced precipitation heating then excites ascending Rossby waves to its west and north of the equator where the Bay of Bengal-India heat source locates, causing enhanced rainfall over India. Opposite anomalies occur during an El Niño episode. The coherent change of ISM and EASM in REOF1 reflects the impact of anomalous Indian convection on northeast EASM through a "Silk Road" zonal wave train pattern during boreal summer (Enomoto et al. 2003). This Silk Road wave train pattern is a part of the circumglobal teleconnection (CGT) (Ding and Wang 2005). A schematic diagram illustrating these processes can be found in Wang et al. (2017, Fig. 9).

Ashok et al. (2004) show that when a positive IOD event simultaneously occurs with El Niño, the ENSO influence on ISM can be reduced by introducing an anomalous divergence center in the eastern tropical Indian Ocean. It is also shown that positive IOD events amplify the ENSO-induced dryness over the MC. Nevertheless, the ENSO influence seems to remain largely dominant and robust. Mooley and Munot (1993) have shown that the ISM is consistently negatively correlated with a developing ENSO from 1871 to 1990.

REOF2 (Fig. 1a) represents strengthening of the subtropical EASM rain belt during a rapid decay of El Niño when the heat source over the Philippine Sea is suppressed due to enhanced WNP subtropical high ( $\mathrm{SH}$ ). The opposite is nearly true during 
the decay of strong La Niña events. During the decaying phase of a strong El Niño, the El Niño-induced WNP anticyclonic anomaly (WNPAC) can interact with underlying dipolar SST anomalies in the Indo-Pacific warm pool, thereby maintaining the WNPAC and leading to a prolonged Niño impact on East Asia (Wang et al. 2000, 2013). A weak El Niño, during its rapid transition to La Niña, may also enhance the postEl Niño summer rainfall over the Yangtze River Catchment, nevertheless through a different physical process: the WNPAC re-emerges as a forced response to the rapid cooling in the central-eastern Pacific (Wang et al. 2017).

Wang et al. (2017) have shown that over the past 60 years, the only robust seasonal signal for EASM is the wet (dry) anomalies over central North China during the La Niña (El Niño) developing summer. The response of rainfall variability over the middle and lower reach of the YRV during the ENSO decaying summer largely depends on the ENSO intensity (Wang et al. 2017). Besides, the migratory nature of the EA subtropical frontal zone and the associated rainfall variability on the subseasonal timescale also contributes to the relatively weak PC2-ENSO correlation (Table 1). The background mean state in tropical and North Pacific SSTs also plays a role in altering WNP convective anomaly (Wu and Wang 2002) and thus changing the EASM-ENSO relationship.

It seems that the afore-discussed mechanisms for the modern AM-ENSO relationship can, to a great extent, work for the past as well. During the ENSO developing phase, the ENSO induced chain reaction of precipitation anomalies over the MC and through India to northern China is shown by the overall coherent variations displayed in Fig. $7 \mathrm{a}-\mathrm{c}$. The ENSO-rainfall relations over the MC and India are less coherent and largely non-linear, maybe reflecting the aforementioned IOD influences on the ISM. The in-phase and opposite-sign relationship over central arid Asia (Fig. 7d) can be explained by the monsoon-desert coupling mechanism (Hoskins and Wang 2006), which attributes the drying to the interaction between the anomalous monsoon heatinginduced circulation anomalies and the mean westerly flow. It is quite remarkable that despite of the large uncertainties associated with proxy reconstructions, such a chain-reaction system is still discernable and sustains for almost five centuries. During the ENSO decaying phase, the large interdecadal to centennial variations over the past 500 years (Fig. 9) echo the highly variable EASM-decaying ENSO relationship in the present. Such a relationship is proved to be rather fragile and nonstationary over time.

\subsection{Possible reasons for the multidecadal to centennial changes of the monsoon-ENSO relationship}

It is a great challenge to fully explain the causes of secular (interdecadal-centennial) changes in the RAP-ENSO relationship shown in Figs. 7 and 9, because (1) the fitted reconstruction data are insufficient and different proxies usually have large discrepancies, and (2) models have limited skills in simulating interdecadal-centennial variations. Here we further examine the Pacific Decadal Oscillation (PDO) and long-term changes in ENSO intensity as an effort to detect possible factors that may contribute to low-frequency variations of the monsoon-ENSO relationship. The external effective radiative forcing is not examined because it is not independent from the ENSO intensity on this timescale $(\mathrm{r}=0.62, \mathrm{p}<0.01)$.

Figure 10a shows normalized PDO induces derived from five groups and their ensemble mean. Note the considerable spread among the five proxy PDO indices. Nevertheless, similar evolutions between the PDO and the ISM-developing ENSO relationship (Fig. 7b) as well as the EASMdeveloping ENSO relationship (Fig. 7c) are notable. The correlation between the ISM-ENSO (EASM-ENSO) relation and 51-year smoothed PDO ensemble is $0.64(0.77$, $\mathrm{p}<0.01)$. In particular, the strengthening ISM-ENSO relation at 1620 coincides a phase reversal of the PDO. The weakened EASM-ENSO relation from 1900 to 1940 is also accompanied by a period of positive PDO.

The ENSO intensity (Fig. 10b) seems to be linked to the MC rainfall-developing ENSO relation (Fig. 7a). After around 1860, strengthened ENSO corresponds to strengthened monsoon-ENSO tie over the MC (Fig. 7a). The correlation between $\mathrm{MC}$ rainfall-ENSO relation and the ENSO intensity is $-0.43(\mathrm{p}<0.05)$ on the multidecadal to centennial scale. For the AM rainfall-decaying ENSO relationship

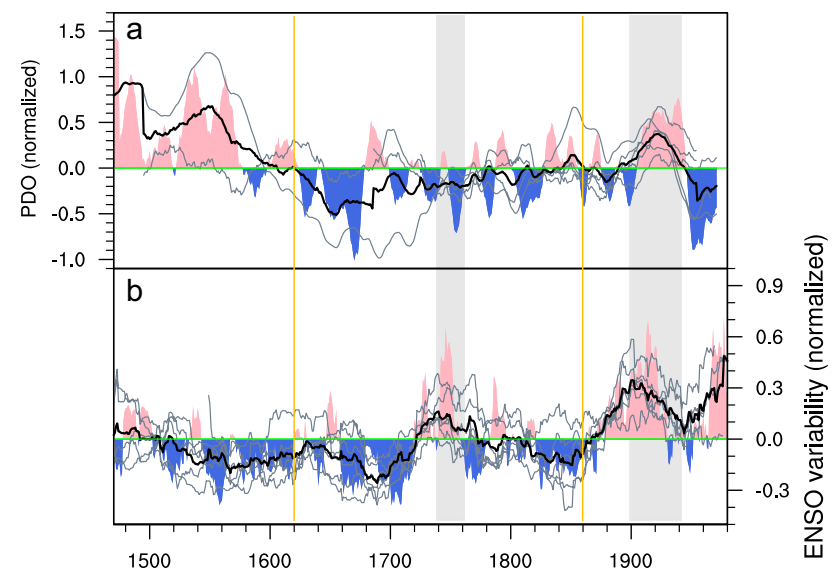

Fig. 10 11-year (shadings) and 51-year smoothed normalized PDO indices (a) and ENSO amplitude variability (b). Black lines are ensemble means. Five PDO indices include D'Arrigo et al. (2001, 1700 and 1790 reconstructions), MacDonald and Case (2005), Shen et al. (2006), and Biondi et al. (2001). Six Niño indices include D'Arrigo et al. (2005), Cook et al. (2008), Braganza et al. (2009), Li et al. (2011, 2013), Emile-Geay et al. (2013). Gray bars mark the characteristic periods of 1740-1760, and 1900-1940; yellow lines mark the characteristic years 1620 and 1860 
(Fig. 9), it seems that its centennial change may be more related to the centennial variations of the ENSO intensity (Fig. 10b). The correlations of 51-year smoothed ENSO intensity are $0.25(\mathrm{p}<0.20)$ with the YRV-SEC rainfallENSO relation, $0.40(\mathrm{p}<0.10)$ with both those of the MC rainfall and Central Asian rainfall. The largely strengthened ENSO amplitude since 1720 (Fig. 10b) could cause the dramatic sign-changes in monsoon-ENSO relationship around 1740 and 1760 over the MC (Fig. 9b) and YRV-SEC (Fig. 9a) regions.

Due to the limited quality of the proxy data, the causes of the secular change of the AM-ENSO relationship discussed above remain to be confirmed. The causality between PDO and ENSO-AM relationship remains elusive. It is likely that the centennial variations of the ENSO intensity are more important in modulating the monsoon-ENSO relations during the decaying phase of an El Niño.

\section{Conclusion}

The RAP is proved to have recorded the phase-dependent influences of the ENSO on Asian summer precipitation since 1470. Two major modes of interannual variability are identified. The first mode features coherent variations over the MC, India and northern China, and this "chain reaction" is associated with the developing phase of the low-frequency (5-year) component of ENSO. The second mode shows variation centers over the YRV, which is associated with the decaying phase of ENSO and/or the rapid transition of the biennial component of ENSO. Mechanisms for the modern monsoon-ENSO relationship can be extended back in time, and still provide reasonable explanations for the past monsoon behavior before the instrumental period.

During the ENSO developing phase, the AM-ENSO relationship is relatively stable albeit periods of breaks occasionally take place on the interdecadal timescale. The MC-Indianorthern China chain-reaction in response to ENSO tends to be largely steady since around 1620. Meanwhile, the MC rainfall-ENSO relation is more robust than the ISM-ENSO relation, likely due to the counter-impact of the IOD on the ISM. Of interest is that the ENSO tie with the Indian and northern China rainfall tends to be strengthened in the early 1600 s, concurring with the abrupt strengthening of the Indian summer monsoon.

During the ENSO decaying phase, the rainfall-ENSO relationship has gone through large interdecadal to centennial changes over the YRV-SEC, the MC and the central Asia for the past five centuries. An evident sign reversal in the rainfall-ENSO relationship over the YRV-SEC and the MC occurred from 1740 to 1760 , which is suggested by various Niño proxies and their ensemble.
It remains a great challenge to understand the causes of the secular (interdecadal-centennial) changes in the Asian summer monsoon (ASM)-ENSO relationship. Nevertheless, evidence has presented to show that Pacific Decadal Oscillation is linked to multidecadal to centennial change of ASM-ENSO relationship (Fig. 10a), especially for the ISM and EASM during the ENSO developing phase (Fig. 7b, c). The strengthening ISM-ENSO relation at 1620 coincides with a phase reversal of PDO (Fig. 10a); the weak EASMENSO relation from 1900 to 1940 also concurs with a positive phase of PDO (Fig. 10a). During the ENSO decaying phase (Fig. 9), on the other hand, the centennial reversal of sign of the YRV-SEC (MC) rainfall-ENSO relation from 1740 to 1760 seems to follow an overall strengthening of ENSO intensity since 1720 (Fig. 10b).

The present results are made based on the ensembles of various proxy reconstructions with considerable spreads. While it does not clarify the reasons for the secular change of the complicated AM-ENSO relationship, it is a comprehensive documentation of the interdecadal through centennial changes of the ENSO association with various Asian monsoon components. While one should not overlook the effects of external forcing such as solar-volcanic and greenhouse gases, fluctuations of the ASM-ENSO relationship on the multidecadal to centennial scale are likely dominated by internal processes within the coupled climate system. However, concrete conclusions can only be drawn after further testing with plausible numerical simulations. Future research should continue focusing on discovering possible causes of the low-frequency changes in the monsoon-ENSO relationship using general circulation models and paleoclimate proxy reconstructions.

Acknowledgements This work is supported by the National Natural Science Foundation of China (Grant No. 41420104002), the National Key Research and Development Program of China (Grant No. 2016YFA0600401) and the National Science Foundation (Climate Dynamics Division) Award \# AGS-1540783. We thank the two anonymous reviewers for their comments to improve the manuscript. This is publication No. 10430 of the SOEST, publication No. 1336 of IPRC, and publication No. 232 of Earth System Modeling Center (ESMC).

Open Access This article is distributed under the terms of the Creative Commons Attribution 4.0 International License (http://creativeco mmons.org/licenses/by/4.0/), which permits unrestricted use, distribution, and reproduction in any medium, provided you give appropriate credit to the original author(s) and the source, provide a link to the Creative Commons license, and indicate if changes were made.

\section{References}

Anderson DM, Overpeck JT, Gupta AK (2002) Increase in the Asian southwest monsoon during the past four centuries. Science 297:596-599. https://doi.org/10.1126/science.1072881 (80-) 
Ashok K, Saji NH (2007) On the impacts of ENSO and Indian Ocean dipole events on sub-regional Indian summer monsoon rainfall. Nat Hazards 42:273-285. https://doi.org/10.1007/s1106 9-006-9091-0

Ashok K, Guan Z, Yamagata T (2001) Impact of the Indian Ocean dipole on the relationship between the Indian monsoon rainfall and ENSO. Geophys Res Lett 28:4499-4502. https://doi. org/10.1029/2001GL013294

Ashok K, Guan Z, Saji NH, Yamagata T (2004) Individual and combined influences of ENSO and the Indian Ocean dipole on the Indian summer monsoon. J Clim 17:3141-3155. https ://doi.org/10.1175/1520-0442(2004)017\%3C3141:IACIO E\%3E2.0.CO;2.

Ashrit RG, Kumar KR, Kumar KK (2001) ENSO-monsoon relationships in a greenhouse warming scenario. Geophys Res Lett 28:1727. https://doi.org/10.1029/2000GL012489

Barnett TP, Dümenil L, Schlese U, Roeckner E, Latif M (1989) The effect of Eurasian snow cover on regional and global climate variations. J Atmos Sci 46:661-686. https://doi.org/10.1175/15200469(1989)046\%3C0661:TEOESC\%3E2.0.CO;2

Berkelhammer M, Sinha A, Mudelsee M, Cheng H, Edwards RL, Cannariato K (2010) Persistent multidecadal power of the Indian Summer Monsoon. Earth Planet Sci Lett 290:166-172. https:// doi.org/10.1016/j.epsl.2009.12.017

Biondi F, Gershunov A, Cayan DR (2001) North Pacific Decadal Climate Variability since 1661. J Clim 14:5-10. https ://doi.org/10.1175/1520-0442(2001)014\%3C0005:NPDCV S\%3E2.0.CO;2

Blanford HF (1884) On the connexion of the Himalaya snowfall with dry winds and seasons of drought in India. Proc R Soc Lond 37:3-22. https://doi.org/10.1098/rspl.1884.0003

Bradley RS, Jonest PD (1993) "Little Ice Age" summer temperature variations: their nature and relevance to recent global warming trends. Holocene 3:367-376. https://doi.org/10.1177/0959683693 00300409

Braganza K, Gergis JL, Power SB, Risbey JS, Fowler AM (2009) A multiproxy index of the El Niño-Southern Oscillation, A.D. 1525-1982. J Geophys Res Atmos. https://doi.org/10.1029/2008J D010896

Chang CP (2004) The East Asian Monsoon. World Scientific Publishing Company, Singapore

Chang CP, Harr P, Ju J (2001) Possible roles of Atlantic circulation on the weakening Indian monsoon rainfallENSO relationship. J Clim 14:2376-2380. https://doi. org/10.1175/1520-0442(2001)014<2376:PROACO >2.0.CO;2

Chen LX, Dong M, Shao YN (1992) The characteristics of interannual variations on the East Asian monsoon. J Meteorol Soc Jpn Ser II 70:397-421

Cook ER, D'Arrigo RD, Anchukaitis KJ (2008) ENSO reconstructions from long tree-ring chronologies: unifying the differences. In: Diaz HF (ed)

Cook ER, Anchukaitis KJ, Buckley BM, D'Arrigo RD, Jacoby GC, Wright WE (2010) Asian monsoon failure and megadrought during the last millennium. Science 328:486-489. https://doi. org/10.1126/science. 1185188

D'Arrigo R, Villalba R, Wiles G (2001) Tree-ring estimates of Pacific decadal climate variability. Clim Dyn 18:219-224. https://doi. org/10.1007/s003820100177

D'Arrigo R, Cook ER, Wilson RJ, Allan R, Mann ME (2005) On the variability of ENSO over the past six centuries. Geophys Res Lett 32:1-4. https://doi.org/10.1029/2004GL022055

Ding Y, Chan JCL (2005) The East Asian summer monsoon: an overview. Meteorol Atmos Phys 89:117-142. https://doi.org/10.1007/ s00703-005-0125-z
Ding Q, Wang B (2005) Circumglobal teleconnection in the Northern Hemisphere summer. J Clim 18:3483-3505. https://doi. org/10.1175/JCLI3473.1

Emile-Geay J, Cobb KM, Mann ME, Wittenberg AT (2013) Estimating central equatorial pacific SST variability over the past millennium. Part II: reconstructions and implications. J Clim 26:2329-2352. https://doi.org/10.1175/JCLI-D-11-00511.1

Enomoto T, Hoskins BJ, Matsuda Y (2003) The formation mechanism of the Bonin high in August. Q J R Meteorol Soc 129:157-178. https://doi.org/10.1256/qj.01.211

Fang K, Seppä H, Chen D (2015) Interdecadal hydroclimate teleconnections between Asia and North America over the past 600 years. Clim Dyn 44:1777-1787. https://doi.org/10.1007/s0038 2-014-2266-6

Feba F, Ashok K, Ravichandran M (2018) Role of changed IndoPacific atmospheric circulation in the recent disconnect between the Indian summer monsoon and ENSO. Clim Dyn. https://doi. org/10.1007/s00382-018-4207-2

Feng S, Hu Q, Wu Q, Mann ME (2013) A gridded reconstruction of warm season precipitation for asia spanning the past half millennium. J Clim 26:2192-2204. https://doi.org/10.1175/JCLID-12-00099.1

Fu C, Teng X (1988) The relationship between ENSO and climate anomaly in China during the summer time (in Chinese). Sci Atmos Sin, Special Issue:133-141

Hahn DG, Shukla J (1976) An apparent relationship between Eurasian snow cover and Indian monsoon rainfall. J Atmos Sci 33:24612462. https://doi.org/10.1175/1520-0469(1976)033\%3C246 1:AARBES\%3E2.0.CO;2

Hoskins BJ, Wang B (2006) Large-scale atmospheric dynamics. In: The Asian monsoon. Springer, Berlin, pp 357-415

Huang R-H, Wu Y (1989) The influence of ENSO on the summer climate change in China and its mechanism. Adv Atmos Sci 6:21-32. https://doi.org/10.1007/BF02656915

Kathayat $\mathrm{G}$ et al (2016) Indian monsoon variability on millennialorbital timescales. Sci Rep. https://doi.org/10.1038/srep24374

Keshavamurty R (1982) Response of the atmosphere to sea surface temperature anomalies over the equatorial Pacific and the teleconnections of the Southern Oscillation. J Atmos Sci 39:1241-1259. https://doi.org/10.1175/1520-0469(1982)039\%3C1241:ROTAT S\%3E2.0.CO;2

Kripalani RH, Kulkarni A (2001) Monsoon rainfall variations and teleconnections over South and East Asia. Int J Climatol 21:603-616. https://doi.org/10.1002/joc.625

Krishnamurthy L, Krishnamurthy V (2014) Influence of PDO on South Asian summer monsoon and monsoon-ENSO relation. Clim Dyn 42:2397-2410. https://doi.org/10.1007/s00382-013-1856-z

Kumar KK, Rajagopalan B, Cane MA (1999) On the weakening relationship between the indian monsoon and ENSO. Science 284:2156-2159. https://doi.org/10.1126/science.284.5423.2156 (80-)

Lau NC, Nath MJ (2000) Impact of ENSO on the variability of the Asian-Australian Monsoons as simulated in GCM experiments. J Clim 13:4287-4309. https://doi.org/10.1175/15200442(2000)013\%3C4287:IOEOTV\%3E2.0.CO;2

Lau K-M, Sheu PJ (1988) Annual cycle, quasi-biennial oscillation, and southern oscillation in global precipitation. J Geophys Res Atmos 93:10975-10988. https://doi.org/10.1029/JD093iD09p10975

Lau K-M, Wu HT (2001) Principal modes of rainfall-SST variability of the Asian summer monsoon: a reassessment of the Monsoon-ENSO relationship. J Clim 14:2880-2895. https ://doi.org/10.1175/1520-0442(2001)014\%3C2880:PMORS $\mathrm{V} \% 3 \mathrm{E} 2.0 . \mathrm{CO} ; 2$

Li T, Wang B, Chang C-P, Zhang Y (2003) A Theory for the Indian Ocean dipole-zonal mode. J Atmos Sci 60:2119-2135. https 
://doi.org/10.1175/1520-0469(2003)060\%3C2119:ATFTI O\%3E2.0.CO;2

Li J, Xie SP, Cook ER, Huang G, D'arrigo R, Liu F, Ma J, Zheng XT (2011) Interdecadal modulation of El Niño amplitude during the past millennium. Nat Clim Change 1:114-118. https://doi. org/10.1038/nclimate1086

Li J et al. (2013) El Niño modulations over the past seven centuries. Nat Clim Chang 3:822-826. https://doi.org/10.1038/nclimate1936

Li J, Xie SP, Cook ER (2014) El Niño phases embedded in Asian and North American drought reconstructions. Quat Sci Rev 85:20-34. https://doi.org/10.1016/j.quascirev.2013.11.014

MacDonald GM, Case RA (2005) Variations in the Pacific Decadal Oscillation over the past millennium. Geophys Res Lett 32:L08703. https://doi.org/10.1029/2005GL022478

Mann ME, Gille E, Overpeck J, Gross W, Bradley RS, Keimig FT, Hughes MK (2000) Global temperature patterns in past centuries: an interactive presentation. Earth Interact 4:1-1. https ://doi.org/10.1175/1087-3562(2000)004\%3C0001:GTPIP C\%3E2.3.CO;2

McGregor S, Timmermann A, Timm O (2010) A unified proxy for ENSO and PDO variability since 1650. Clim Past 6:1-17. https ://doi.org/10.5194/cp-6-1-2010

Mooley DA, Munot AA (1993) Variation in the relationship of the Indian summer monsoon with global factors. Proc Indian Acad Sci Earth Planet Sci 102:89-104. https://doi.org/10.1007/BF028 39184

Mooley DA, Parthasarathy B (1984) Indian summer monsoon and the east equatorial pacific sea surface temperature. Atmos Ocean 22:23-35. https://doi.org/10.1080/07055900.1984.9649182

Palmer TN, Č Branković, P Viterbo, MJ Miller (1992) Modeling interannual variations of summer monsoons. J Clim 5:399-417. https:// doi.org/10.1175/1520-0442(1992)005<0399:MIVOSM>2.0.CO;2

Rasmusson EM, Carpenter TH (1983) The relationship between eastern equatorial pacific sea surface temperatures and rainfall over India and Sri Lanka. Mon Weather Rev 111:517-528. https://doi. org/10.1175/1520-0493(1983)111<0517:TRBEEP>2.0.CO;2

Rayner NA (2003) Global analyses of sea surface temperature, sea ice, and night marine air temperature since the late nineteenth century. J Geophys Res 108: 4407. https://doi.org/10.1029/2002JD002670

Ropelewski CF, Halpert MS (1987) Global and regional scale precipitation patterns associated with the El-Nino/southern oscillation. Mon Weather Rev 115:1606-1626. https://doi.org/10.1175/15200493(1987)115\%3C1606:GARSPP\%3E2.0.CO;2

Saji NH, Goswami BN, Vinayachandran PN, Yamagata T (1999) A dipole mode in the tropical Indian ocean. Nature 401:360-363. https://doi.org/10.1038/43855

Schneider U, Becker A, Finger P, Meyer-Christoffer A, Rudolf B, Ziese M (2015) GPCC full data reanalysis version 7.0 at 0.5 : monthly land-surface precipitation from rain-gauges built on GTS-based and historic data. https://doi.org/10.5676/DWD_GPCC/FD_M_ V7_050. https://www.esrl.noaa.gov/psd/data/gridded/data.gpcc. html. Accessed 3 Jan 2016

Seber GA (1984) Multivariate Observations. In: Seber GAF (ed) Wiley, Hoboken, NJ, USA, p 686

Shen C, Wang W-C, Gong W, Hao Z (2006) A Pacific Decadal Oscillation record since $1470 \mathrm{AD}$ reconstructed from proxy data of summer rainfall over eastern China. Geophys Res Lett 33:L03702. https://doi.org/10.1029/2005GL024804

Shi F, Zhao S, Guo Z, Goosse H, Yin Q (2017) Multi-proxy reconstructions of May-September precipitation field in China over the past 500 years. Clim Past 13:1919-1938. https://doi.org/10.5194/ cp-13-1919-2017

Shi H, Wang B, Cook ER, Liu J, Liu F (2018) Asian summer precipitation over the past 544 years reconstructed by merging tree rings and historical documentary records. J Clim. 31:7845-7861. https ://doi.org/10.1175/JCLI-D-18-0003.1
Shukla J, Mooley DA (1987) Empirical prediction of the summer monsoon rainfall over India. Mon Weather Rev 115: 695-704. https:// doi.org/10.1175/1520-0493(1987)115<0695:EPOTSM>2.0.CO;2

Sikka DR (1980) Some aspects of the large scale fluctuations of summer monsoon rainfall over India in relation to fluctuations in the planetary and regional scale circulation parameters. Proc Indian Acad Sci Earth Planet Sci 89:179-195. https://doi.org/10.1007/ BF02913749

Sinha A, Cannariato KG, Stott LD, Cheng H, Edwards RL, Yadava MG, Ramesh R, Singh IB (2007) A 900-year (600-1500 A.D.) record of the Indian summer monsoon precipitation from the core monsoon zone of India. Geophys Res Lett. https://doi. org/10.1029/2007GL030431

Sinha A, Berkelhammer M, Stott L, Mudelsee M, Cheng H, Biswas J (2011) The leading mode of Indian summer monsoon precipitation variability during the last millennium. Geophys Res Lett. https://doi.org/10.1029/2011GL047713

Spath H (1985) Cluster dissection and analysis: theory, FORTRAN programs, examples. Halsted Press, New York, p 226

Stahle DS et al. (1998) Experimental dendroclimatic reconstruction of the Southern Oscillation. Bull Am Meteorol Soc 79:2137-2152. https://doi.org/10.1175/1520-0477(1998)079<2137:EDROTS> 2.0.CO;2

Tejavath CT, Karumuri A, Chakraborty S, Ramesh R (2017) The Indian summer monsoon climate during the Last Millennium, as simulated by the PMIP3. Clim Past Discuss. https://doi.org/10.5194/ cp-2017-24

Walker GT, Bliss EW (1932) World weather V-NAO. Mem R Meteorol Soc IV:54-84. https://doi.org/10.1002/qj.49705422601

Wang B (2006) The Asian monsoon. Springer, Berlin

Wang B, Fan Z (1999) Choice of South Asian summer monsoon indices. Bull Am Meteorol Soc 80:629-638. https://doi. org/10.1175/1520-0477(1999)080<0629:COSASM > 2.0.CO;2

Wang B, Li T (2004) East Asian monsoon and ENSO interaction. In: Chang CP (ed) East Asian monsoon. World Scientific Publishing Company, Singapore, pp 172-212

Wang B, Wu R, Fu X (2000) Pacific-East Asian teleconnection: how does ENSO affect East Asian climate? J Clim, 13:1517-1536. https://doi.org/10.1175/1520-0442(2000)013<1517:PEATHD> 2.0.CO;2

Wang B, Wu R, Lau K-M (2001) Interannual variability of the Asian summer monsoon: contrasts between the Indian and the Western North Pacific-East Asian Monsoons. J Clim 14 4073-4090. https:// doi.org/10.1175/1520-0442(2001)014<4073:IVOTAS>2.0.CO;2

Wang B, Wu R, Li T (2003) Atmosphere-warm ocean interaction and its impacts on Asian-Australian monsoon variation. J Clim 16:11951211. https://doi.org/10.1175/1520-0442(2003)16<1195:AOIAI $\mathrm{I}>2.0 . \mathrm{CO} ; 2$

Wang B, Yang J, Zhou T, Wang B (2008) Interdecadal changes in the major modes of Asian-Australian monsoon variability: Strengthening relationship with ENSO since the late 1970s. J Clim 21:1771-1789. https://doi.org/10.1175/2007JCLI1981.1

Wang B, Xiang B, Lee J (2013) Subtropical high predictability establishes a promising way for monsoon and tropical storm predictions. Proc Natl Acad Sci USA 110:2718-2722. https://doi. org/10.1073/pnas.1214626110

Wang B, Lee J-Y, Xiang B (2015) Asian summer monsoon rainfall predictability: a predictable mode analysis. Clim Dyn 44:61-74. https://doi.org/10.1007/s00382-014-2218-1

Wang B, Li J, He Q (2017) Variable and robust East Asian monsoon rainfall response to El Niño over the past 60 years (1957-2016). Adv Atmos Sci 34:1235-1248. https://doi.org/10.1007/s0037 6-017-7016-3

Webster PJ, Yang S (1992) Monsoon and ENSO: selectively interactive systems. Q J R Meteorol Soc 118:877-926. https://doi. org/10.1002/qj.49711850705 
Webster PJ, Magaña VO, Palmer TN, Shukla J, Tomas RA, Yanai M, Yasunari T (1998) Monsoons: processes, predictability, and the prospects for prediction. J Geophys Res Ocean 103:14451-14510. https://doi.org/10.1029/97JC02719

Webster PJ, Moore AM, Loschnigg JP, Leben RR (1999) Coupled ocean-atmosphere dynamics in the Indian Ocean during 1997-98. Nature 401:356-360. https://doi.org/10.1038/43848

Wilson R, Cook E, D'arrigo R, Riedwyl N, Evans MN, Tudhope A, Rob A (2010) Reconstructing ENSO: the influence of method, proxy data, climate forcing and teleconnections. J Quat Sci 25:6278. https://doi.org/10.1002/jqs.1297

Wu R, Wang B (2002) A contrast of the East Asian summer monsoonENSO relationship between 1962-77 and 1978-93. J Clim 15:32663279, https://doi.org/10.1175/1520-0442(2002)015<3266:ACOTE $\mathrm{A}>2.0 . \mathrm{CO} ; 2$

Yang S (1996) Enso-snow-monsoon associations and seasonal-interannual predictions. Int J Climatol 16 125-134. https://doi.org/10.1002/ (SICI)1097-0088(199602)16:2<125::AID-JOC999>3.0.CO;2-V
Yang F, Shi F, Kang S, Wang S, Xiao Z, Nakatsuka T, Shi J (2013) Comparison of the dryness/wetness index in China with the Monsoon Asia Drought Atlas. Theor Appl Climatol 114:553-566. https://doi.org/10.1007/s00704-013-0858-4

Yang B, Kang S, Ljungqvist FC, He M, Zhao Y, Qin C (2014) Drought variability at the northern fringe of the Asian summer monsoon region over the past millennia. Clim Dyn 43:845-859. https://doi. org/10.1007/s00382-013-1962-y

Yatagai A, Yasunari T (1995) Interannual variations of summer precipitation in the arid/semi-arid regions in China and Mongolia: their regionality and relation to the Asian summer monsoon. J Meteorol Soc Jpn Ser II 73:909-923. https://doi.org/10.2151/ jmsj1965.73.5_909

Zhang R, Sumi A, Kimoto M (1996) Impact of El Nino on the East Asian Monsoon: a diagnostic study of the' $86 / 87$ and' $91 / 92$ events. J Meteorol Soc Jpn 74:49-62. https://doi.org/10.1017/CBO97 81107415324.004 